\title{
Laureano Gómez: violencia y religiosidad
}

\section{Antecedentes}

T aureano Gómez fue el fruto legítimo de la reacción conservadora —frente a una república liberal que no logró consolidar un modelo de democracia basado en la justicia, la libertad y el desarrollo económico. Antes que conservador, Laureano Gómez fue un católico batallador, heredero de los rasgos de la Iglesia combativa del siglo XIx, impulsada especialmente por Pío IX y luego por Pío X ya en el siglo xx, y no de la diplomacia mucho más eficaz de León XIII; una Iglesia misionera, cuya tradición se enlaza con las cruzadas y con la Inquisición. Es la Iglesia paulina que concibe la doctrina de la salvación del alma en virtud de un dios salvador, y la actividad apostólica como una misión para difundir "la verdad". Ese espíritu misionero y apologético triunfó en la Iglesia y originó las cruzadas, la Inquisición y las misiones en América.

Ante las arremetidas reformistas o revolucionarias, la Iglesia católica ha reaccionado de una manera radical, y ha originado contrarreformas o contrarrevoluciones con un espíritu combativo y con la imposición de una autoridad que ha querido restituir el poder perdido. Así, frente a la Reforma protestante iniciada por Martín Lutero, la Iglesia opuso la Contrarreforma católica, en la que se destacan los papas Pío V y Pío VI, la fundación de la Compañía de Jesús, la reforma de la Orden de los Carmelitas, y el auge de la Inquisición en el siglo XVI, y emprendió acciones radicales como el Concilio de Trento y el combate a la herejía. Del mismo modo, frente al espíritu revolucionario y liberal del siglo xix, se levanta un papa como Pío IX, que fue expulsado de Roma a raíz de la revolución de 1848, y regresó decidido a imponer la 
autoridad pontificia y a restaurar la Iglesia. Su papado, el más largo de la historia (del 16 de junio de 1846 al 7 de febrero de 1878, 31 años y medio) se caracterizó por una arremetida contrarrevolucionaria y una combatividad acérrima contra el liberalismo católico, la masonería y el comunismo (Di Stefano, 2015). Cabe detenerse en su diatriba contra el liberalismo católico, citada por Otto Morales Benítez (1998):

Ello se condimenta con escritos de Mariano Ospina Rodríguez como el que tituló "Liberalismo católico". Cita a Pío IX quien contribuye con esta perla: "La verdadera plaga de la Francia es el liberalismo católico". Con mucha energía sigue recalcando que es "tiempo ya de que se piense en extirpar de nosotros esa peste perniciosísima del liberalismo católico, que ha sido anatematizada más de cuarenta veces por ese gran pontífice” (p. 17).

En la encíclica Quanta cura (1864), que contiene el Syllabus complectens praecipuos nostrae aetatis errores, el papa Pío IX arremete contra el espíritu revolucionario de la época, que tuvo expresiones múltiples en 1848, pues empezó en Francia y se extendió por toda Europa. En ella, el papa hace una lista de "los principales errores de la época", y con tono inquisitorial condena el comunismo y el socialismo, como ya había proscrito el liberalismo católico:

5. Apoyándose en el funestísimo error del comunismo y el socialismo, aseguran que "la sociedad doméstica debe toda su razón de ser sólo al derecho civil y que, por lo tanto, sólo de la ley civil se derivan y dependen todos los derechos de los padres sobre los hijos y, sobre todo, del derecho de la instrucción y de la educación". Con esas máximas tan impías como sus tentativas, no intentan esos hombres tan falaces sino sustraer, por completo, a la saludable doctrina e influencia de la Iglesia la instrucción y la educación de la juventud, para así inficionar y depravar míseramente las tiernas e inconstantes almas de los jóvenes con los errores más perniciosos y con toda clase de vicios (Pío IX, 1864, párr. 6). 
Este tono apologético inquisitorial lo vamos a encontrar, casi un siglo después, al final de la hegemonía liberal que empieza en 1930, en Laureano Gómez Castro, un militante católico que bebe de esa Iglesia reaccionaria que pretende recuperar su poder. Ya había promovido la Restauración, frente a la república liberal que había empezado Obando. La Iglesia promovió las principales guerras del siglo XIX, con el propósito de recuperar la hegemonía de la educación, los bienes de manos muertas perdidos, el Concordato y el nombre de Dios en el prólogo de la Constitución, como fuente de todo poder. Además, se va lanza en ristre contra el espíritu socialista que quería abolir la propiedad privada, como lo declara el Manifiesto Comunista, pues merodeaba como un fantasma. Contra este espíritu se alzan Pío IX y Pío X. Y esa bandera es recogida por Laureano Gómez desde los años veinte.

El papa León XIII fue más liberal y muchísimo más eficaz. Pese a que no se trata de hacer aquí una historia de los papas, conviene mencionarlo porque es este otro espíritu que ha animado a la Iglesia y que ha dado otros frutos que perduran aún hoy. León XIII expidió la encíclica Rerum novarum (León XIII, 1891), conciliadora con los principios socialistas respecto a la justicia con la clase obrera, pero igualmente condenatoria del ateísmo y del socialismo, aunque permite tender la mano a esta ideología para negociar políticamente. La encíclica reconoce la legitimidad de la propiedad privada, pero critica los "abusos de la explotación capitalista", que reducía a la miseria a los trabajadores. Para solucionar las desigualdades que provocaba el capitalismo, proponía la conformación de asociaciones de obreros, que los trabajadores participaran en el capital de la empresa y que los Estados promulgaran legislaciones basadas en la equidad social (León XIII, 1891). Este espíritu liberal permite que retorne a la Iglesia el proscrito liberalismo católico que había sido excomulgado por Pío IX.

Y para completar el cuadro originado por la Iglesia católica, cabe mencionar las acciones de Pío X (papado 1903 a 1914), que terminaron de armar el espíritu combativo de la militancia católica. Este papa se preocupó por mantener los dogmas y por imponer su autoridad, contrario a la preocupación de León XIII. Sin embargo pasó por alto la separación de la Iglesia y el Estado en Francia, aunque procuró 
orientar los partidos católicos en el mundo, mediante un combate contra el modernismo que florecía entre los teólogos alemanes, italianos y franceses, quienes proponían que la Iglesia se adaptara a los tiempos modernos y planteaban nuevas formas hermenéuticas de los textos bíblicos, como lo había hecho Martín Lutero en su tiempo.

El abate Loisy, promotor de esta perspectiva, fue excomulgado por el papa, que luego escribió la encíclica Pascendi (Pío X, 1907), para condenar el modernismo como "síntesis de todas las herejías", y para imponer la enseñanza de la filosofía escolástica medieval en las escuelas de teología, junto con un juramento antimodernista. Asimismo, atacó las ideas del movimiento agrupado alrededor del periódico $E l$ Sillón, en Francia, promotor de un espíritu democrático, animado por la orientación de León XIII, que había querido frenar los partidos socialistas mediante la promoción de partidos católicos democráticos (Di Stefano, 2015).

Cabe, finalmente, pensar que la Constitución Política de Colombia de 1886 y el movimiento de la Regeneración de la hegemonía conservadora proscribieron al Partido Liberal como fuerza política, lo que provocó la Guerra de los Mil Días, hasta que este partido fue admitido de nuevo a regañadientes en la contienda política. Y la exclusión del liberalismo de la política en Colombia se justificó con la excomunión papal del liberalismo católico (Morales Benítez, 1998).

\section{Laureano, el personaje}

Laureano Eleuterio Gómez Castro nació en Bogotá el 20 de febrero de 1889 y murió en esta misma ciudad el 13 de julio de 1965. Fue formado por los jesuitas en el Colegio Mayor de San Bartolomé y luego estudió Ingeniería Civil en la Universidad Nacional de Colombia. Pronto abandonó su actividad como ingeniero en el Ferrocarril de Antioquia, y fundó el periódico La Unidad, que pocos años después le sirvió para lanzarse a la Cámara de Representantes, a la que llegó cuando tenía 22 años, en 1911. Luego fue diputado a la Asamblea de Cundinamarca. En 1917 propuso un plan de desarrollo económico nacional. A continuación, en el Congreso de la República inició una serie de debates 
contra el gobierno de Marco Fidel Suárez, quien, finalmente, renunció a la presidencia en 1921.

En 1930, el presidente Enrique Olaya Herrera lo nombró ministro plenipotenciario en Alemania, donde Gómez Castro medró ideológicamente bajo la sombra del Partido Nazi, allí obtuvo mayores fuerzas para regresar al país en 1932 — dos años después de haber empezado el que sería el primer gobierno de la hegemonía liberal de los años treinta y cuarenta- y denunciar a esta regencia por considerarla provocadora de una nueva ola de violencia de carácter partidista que, según Gómez, no se veía desde la Guerra de los Mil Días, declarada también, como entonces, por el Partido Liberal.

En los años treinta fue diputado en Antioquia y Santander, luego, senador en dos períodos no consecutivos, fundó en 1936 el periódico El Siglo que le serviría como tribuna para oponerse a los Gobiernos liberales, especialmente el de la Revolución en Marcha, de Alfonso López Pumarejo. Lanzó la candidatura de Mariano Ospina Pérez y lo llevó a la Presidencia de la República para el cuatrienio 1946-1950, y lo sucedió en la presidencia. En el periódico criticó sin par a los que consideraba pérfidos masones liberales o escoria conservadora; a Eduardo Santos cuando fue presidente, a Carlos Lleras Restrepo, a su ministro de Hacienda, y al propio mandatario conservador Ospina Pérez, durante la presidencia que él mismo apoyó.

La muerte del caudillo liberal Jorge Eliécer Gaitán, el 9 de abril de 1948, durante la presidencia de Ospina Pérez, fue el acontecimiento que desató una rebelión popular en Bogotá, como expresión explosiva de la violencia política que se expandía por el país. Las guerrillas conservadoras venían asolando el campo con grupos armados como los pájaros, en el Valle del Cauca, entre los cuales se destacó León María Lozano el "Cóndor", los chulavitas en Boyacá y Cundinamarca, Efraín González, el "Siete Colores”, y otros muchos, en alianza con políticos y terratenientes conservadores interesados en ampliar sus propiedades en el campo. Los liberales respondieron con sus propias guerrillas defensivas locales, como la de Guadalupe Salcedo Unda, comandante supremo de las Fuerzas Armadas Revolucionarias de los Llanos Orientales; Roberto González Prieto, "Pedro Brincos”; William Ángel 
Aranguren, "Desquite”; Teófilo Rojas Varón, “Chispas”, y Jacinto Cruz Usma, "Sangrenegra”, en el Tolima. Poco después, se conformaron las llamadas repúblicas independientes, como la de Marquetalia, en el municipio de Planadas en el Tolima, con el liderazgo de Pedro Antonio Marín Marín, alias "Manuel Marulanda Vélez” o "Tirofijo", y Luis Alberto Morantes Jaimes, alias “Jacobo Arenas”, fundadores posteriormente, ya en el Frente Nacional, de las Farc.

En este panorama político y de violencia en el país, Laureano renunció a su cargo como ministro de Relaciones Exteriores y se refugió en España, ya que no encontraba garantías en Colombia, ni para los conservadores —acusados de ser responsables del magnicidio de Gaitán-, ni para su propia persona, habida cuenta de que en el Bogotazo fueron quemadas su casa en Fontibón y las instalaciones del periódico El Siglo. Durante su estadía en España, estudió el régimen corporativista de Francisco Franco, y lo tomó como modelo para imponerlo posteriormente, durante su presidencia, a través de una asamblea nacional constituyente.

En ese clima de violencia, Laureano subió a la presidencia en 1950, en unas elecciones en las que fue candidato único, puesto que su opositor, el candidato por el Partido Liberal, Darío Echandía, había renunciado a su postulación por las amenazas sobre la vida y la seguridad que pesaban sobre él y su familia; amenazas que avanzarían hasta el punto del asesinato de su hermano, Vicente Echandía. En el año y medio en el que estuvo en el Gobierno, Gómez impulsó obras de infraestructura y trató de organizar su proyecto de una república de gremios.

Con su mandato se identifican los planes: vial nacional, de construcción de oleoductos, de comunicaciones (ferrocarriles) y puertos marítimos; la creación de Ecopetrol, del Banco Popular y del Ministerio de Fomento. El país avanzó en el desarrollo del campo. Los índices económicos señalaron avance y bonanzas en la economía (Ayala Diago, 1999).

Sin embargo, Gómez fue acusado por la oposición de haber establecido un esquema de represión contra los liberales y los comunistas, a quienes habría perseguido mediante un servicio secreto agenciado por el Gobierno, con la colaboración de los chulavitas que se habían distinguido por sus acciones criminales clandestinas en la violencia anterior al 9 de abril de 1948; por su parte, fue él quien también acusó a 
estas colectividades políticas de haber iniciado la violencia contra el Estado. Asimismo, su periodo ha sido considerado por muchos analistas como una "dictadura civil", pues restringió los poderes legislativo y judicial, otorgó facultades especiales al ejecutivo y limitó un conjunto de libertades civiles, en aras de solventar las situaciones de crisis del momento. En 1951, un ataque cardíaco lo obligó a retirarse de la Presidencia, en la cual fue sustituido por su designado, Rafael Urdaneta Arbeláez. Dos años más tarde, en 1953, quiso retomar el poder, pero pocas horas después de su retorno, el general Gustavo Rojas Pinilla lo destituyó del mando mediante un golpe militar.

Desde ese momento, hasta su muerte, en 1965, siguió liderando el Partido Conservador. Durante el gobierno de Rojas Pinilla, firmó con Alberto Lleras Camargo el Pacto de Benidorm, y luego el Pacto de Sitges, cuando el dictador Rojas Pinilla fue depuesto por una Junta Militar. En este último pacto, se diseñó el Frente Nacional, en el que los dos partidos tradicionales se alternaron el gobierno durante 16 años.

\section{El significado de la violencia para Laureano Gómez}

Laureano Gómez acusó en repetidas ocasiones al Partido Liberal de incitar a la violencia, e ignoró de manera insistente las provocaciones conservadoras, originadas en los púlpitos, por una declaración de guerra que nunca fue oficial ni por la Iglesia ni por el Estado.

En esta apreciación de Laureano Gómez se oculta la ola de violencia que produjeron en los años veinte muchos terratenientes conservadores que se dedicaron a expropiar tierras de los campesinos. Darío Fajardo (2015) sostiene que, en los años veinte, se confrontaron dos proyectos de sociedad: el primero se basó en "la valoración de la propiedad de la tierra" y el segundo en la consolidación de un desarrollo industrial y de una clase media rural. El valor de la propiedad de la tierra provocó una ola de expropiaciones armadas a los campesinos y a los territorios de los antiguos resguardos indígenas coloniales, ahora considerados baldíos, gracias al establecimiento en la Constitución política vigente (1886), de que no habría en Colombia bienes raíces que no fueran libres de enajenación (artículo 37). El otro pilar que sostenía 
el proyecto de sociedad propuso, siguiendo a Fajardo, la "construcción de una economía nacional apoyada en desarrollos industriales y en una sólida clase media rural” (p. 4), lo que fue promovido por personajes de los dos partidos, como el conservador Carlos E. Restrepo, que fue presidente entre 1910 y 1914, y el liberal Alejandro López Restrepo que tuvo una activa participación política en Antioquia, a raíz de la construcción del ferrocarril y de sus propuestas que trajo de México. Estos dos modelos, sin embargo, fueron tomando forma en cabeza de los partidos y el segundo se concretó en la Ley 200 de 1936 o Ley de Tierras, en la que se intentaba remediar el conflicto desatado durante la hegemonía conservadora, especialmente en el último decenio. Según Fajardo, la actividad modernizadora retrocedió ante el empuje de las fuerzas tradicionales de corte colonial que procuraron apropiarse de la tierra:

Las caracterizaciones de los primeros decenios del siglo $\mathrm{Xx}$ presentan un panorama de tensiones generadas por la monopolización de la propiedad, el desorden de las formas de apropiación de las tierras baldías y la ausencia de legitimidad de la propiedad ${ }^{1}$, así como a la persistencia de formas de poder asociadas igualmente a la gran propiedad y ejercidas sin sujeción a un código laboral. Estos procesos habrían de agravarse con el paso de los años como resultado de las mayores presiones sobre la tierra, derivadas de los incrementos de los precios del café, principal exportación del país (Fajardo, 2015, p. 8).

En este mismo sentido, Javier Giraldo S. J. (2015) invoca una coincidencia entre los autores que estudian la violencia en Colombia en que esta empezó en los años veinte, con las acciones de los terratenientes por apropiarse de las tierras de los campesinos. Lo mismo dicen Alfredo Molano (1978) y Sergio de Zubiría Samper (2015), quien

1 Ver LeGrand, Catherine y Palacios, Marco (2011). ¿De quién es la tierra? Propiedad, politización y protesta campesina en la década de 1930. Fondo de Cultura Económica, Bogotá, p. 32; Bergquist, Charles (1981). Café y conflicto en Colombia, 1886-1910. La guerra de los mil dias: sus antecedentes y consecuencias. FAES, Medellín (nota del texto citado). 
destaca la importancia que le da el investigador Carlos Medina al levantamiento del indígena Manuel Quintín Lame durante el gobierno de José Vicente Concha (1914-1918), en su lucha por los derechos de los pueblos indígenas a la tierra.

Estos hechos de violencia por la concentración de la tierra eran, al parecer, legítimos para Laureano Gómez, que no los menciona como hechos de violencia en el país, y acusa, en cambio, al gobierno de Olaya Herrera de provocar la violencia en 1932. Para comprender esta posición que parece provenir de una doble moral, conviene hacerle un seguimiento al pensamiento de Gómez, insertado en el debate dentro de la Iglesia católica desde el siglo xIx, que se esbozó en la primera parte de este capítulo.

\section{La tradición maniquea de la Iglesia}

El maniqueísmo fue condenado por la Iglesia como herejía en el año 382. Se relata que fue Teodosio, el primer emperador cristiano, quien consideró la herejía como un anatema. La declaración de herejía incluyó a los encratitas, los sacóforos y los maniqueos (Enciclopedia católica, 2015). Todas estas tendencias, consideradas por la Iglesia como herejías, provenían de los gnósticos que heredaron a estas sectas el dualismo como fundamento del universo. Los maniqueos, llamados así por Mani o Maneo en el siglo III, fueron los más duraderos y los que formalizaron de manera más clara el dualismo. Este consiste en que reconocen un principio absoluto del bien, que es Dios, y un principio absoluto del mal, que es el demonio, el maligno, la serpiente antigua o Satanás. Para los maniqueos, estos dos son principios sustanciales que luchan a muerte por toda la eternidad. Es decir, esta es una corriente platónica del cristianismo primitivo. San Agustín de Tagaste fue inicialmente maniqueo y, tras su conversión al cristianismo paulino, empezó a combatir esta herejía. Su principal obra que trata el tema es De las costumbres de la Iglesia católica y de las costumbres de los maniqueos (Agustín de Tagaste, 394/2015). En esta obra, San Agustín muestra cómo para los maniqueos hay dos dioses y define el mal como ausencia de bien, no como un principio absoluto. Pero el bien, en cambio, sí proviene del bien sustancial, del principio absoluto 
del bien, que es un ser perfecto, y que no es otro que Dios. Es decir, la lucha de Agustín contra el maniqueísmo se queda a medio camino porque, en todo caso, subsiste en él la idea platónica de una esencia pura del bien, aunque pretende destruir la noción de una sustancia del mal.

Además, en la tradición paulina de Agustín la lucha contra el pecado es la lucha contra el cuerpo, puesto que el alma inmortal es pura. En La ciudad de Dios (403/2007), traza el programa de la historia para Occidente durante dieciocho siglos al menos: nacimos de Dios que está fuera del tiempo y transitamos en el tiempo, que es el pecado, y nos dirigimos a la ciudad de Dios que está fuera del tiempo. En esta perspectiva, que es de Pablo de Tarso, hay encerrado un dualismo maniqueo, puesto que se establece que el cuerpo y el alma luchan hasta que el alma puede sumergirse en Dios. El cuerpo es el pecado y el alma es de Dios. De modo que Agustín, que combate el maniqueísmo como su herejía original, define el mal como ausencia del bien, y aunque se opone a la idea de los dos dioses del maniqueísmo, incurre en una idea maniquea, inspirado en Pablo. El viejo Satanás es sustituido por la carne, por la concupiscencia del cuerpo, donde reside el pecado. Por eso, conciben a María como virgen, que sigue siendo virgen aún después de tener un hijo, porque ese hijo es Dios, es decir, no es presa de la concupiscencia de la carne. La lucha, entonces, será contra el pecado y, por tanto, contra toda herejía... y contra el cuerpo. Y este es el programa que traza la Iglesia en el Concilio de Hipona y en los dos concilios de Cartago, bajo la batuta de Agustín.

Es preciso hacer una consideración más sobre el maniqueísmo, antes de proseguir con nuestro personaje. Cuando el maniqueísmo enfrenta los dos principios, el bien y el mal, enfrenta entidades, cosas, Dios y el diablo. Y esto porque no se trata de un principio ético en el que se valoran las acciones humanas, sino de un principio ontológico del bien y del mal. Entonces, se habla de buenos y de malos, y quienes se enfrentan son los buenos contra los malos. Es decir, los malos hacen cosas malas y los buenos, cosas buenas. Esta idea es completamente actual, como herencia del viejo maniqueísmo. Cuando el presidente Bush hijo, en su discurso ante el Congreso de los Estados Unidos al día siguiente de los sucesos del 11 de septiembre de 2001, declaró la guerra contra el 
terrorismo, invocó un principio absoluto: la democracia, la civilización contra el mal que es el terrorismo. De hecho, invoca a Dios y dice que en esta guerra "Dios no es neutral". Poco después, en su discurso sobre el estado de la Unión, trazó el llamado "eje del mal” que incluía a Corea del Norte, Irán e Irak, al que luego le adicionó otros países, entre ellos Libia, Cuba y Siria. La lucha, entonces, es contra el terrorismo que es el mal. Ahí está plasmado el principio maniqueo en todo su significado.

Ahora bien, siguiendo esta lógica, es preciso reconocer que toda guerra es santa. No es posible convocar a una nación o a un continente o al mundo entero a luchar contra los árabes para quitarles el petróleo que abunda bajo las arenas de sus desiertos. Nadie se alistaría en ese ejército. Para luchar contra los árabes, es necesario declararlos como pertenecientes a la barbarie de "un rincón oscuro de la humanidad", como los calificó Bush hijo, representantes del terrorismo, es decir, del mal. Y todas las guerras se declaran en nombre de principios semejantes: la patria, la civilización, la democracia, la libertad, la independencia...

Pues bien, esa fue la lógica de la Iglesia durante el siglo XIX, a través de Pío IX y luego, en el siglo xx, de Pío X. Así trazó el programa para el ejército de los buenos, es decir, de los católicos, que bajo esa bandera han venido declarándole la guerra al mal desde la Edad Media con las cruzadas, luego con la Inquisición y más adelante contra el liberalismo y el socialismo. Ellos son los malos. Nosotros, la Iglesia de Dios, del principio absoluto del bien, somos los buenos. Y aquí surge otro principio maniqueo: cuando un malo mata a un bueno, eso está mal, porque proviene del principio del mal. Pero cuando un bueno mata a un malo, eso está bien, porque se hace en nombre del principio absoluto del bien, es decir, en nombre de Dios. El mismo acto de matar tiene un signo de bueno o malo dependiendo de quién lo haga. De esta forma, en los noticieros de televisión, cuando un terrorista, es decir, un guerrillero de las Farc o del ELN mata a un soldado, eso se llama "asesinato". Pero cuando un soldado mata a un guerrillero, eso se llama "darle de baja a un terrorista".

Y esa fue la lógica de Laureano Gómez Castro que, como se dijo al principio, fue más un católico militante que un conservador. Como católico, pide que se apoye al Partido Conservador, y no a la inversa: 
Dejémonos de sofismas: sin religión no hay justicia, sin esta la sociedad civilizada es imposible. El Partido Conservador a pesar de cuanto contra él se escriba y se diga es el único que puede garantizar la paz y mantener el orden social... Mientras sea el Partido Conservador el amigo de las instituciones católicas a éste apoyaremos los católicos (Gómez, 1928, p. 49).

En su discurso de posesión como presidente ante la Corte Suprema de Justicia (fue así porque el gobierno anterior de Mariano Ospina Pérez había disuelto el Congreso como medida de defensa nacional), Laureano Gómez dijo lo siguiente, en defensa de la patria:

Las gloriosas tradiciones de la patria estuvieron suficientemente ancladas en la conciencia del pueblo para poder resistir victoriosamente los embates con que se quiso colocar la nación sobre la resbaladiza pendiente de un materialismo pragmático cuya proclividad ineludible habría de arrastrarnos al aherrojamiento del estado marxista. Cuando se borró el nombre de Dios del preámbulo de la Constitución, cuando se adulteraron los sabios principios que regían la sana y benéfica concordia entre las potestades civiles y las espirituales, cuando la juventud fue sometida en la universidad y en las escuelas normales a un desembozado magisterio de naturalismo y ateísmo, adelantaba un empecinado proceso de desfiguración del alma nacional y destrucción de nuestra noble patria libre y cristiana, dándonos en cambio una estructura contrahecha que forzara al pueblo a transitar rencorosos cambios revolucionarios. Pero la cívica cultura de nuestra nación no era superficial, sino tenía raíces fuertes y profundas. Por eso fue posible que el proditorio intento fracasara (Gómez, 1950, \3).

En la perspectiva maniquea, el mal siempre tiene la iniciativa de la agresión, y por eso Laureano Gómez nunca reconoce que fue su Iglesia la que declaró la guerra contra el Estado laico que quisieron imponer los liberales en el siglo xIx. Laureano no reconoce la iniciativa violenta de los terratenientes contra los campesinos en los años veinte, porque para él esa iniciativa era legítima y pertenecía al bien. En cambio, la reacción de defensa de los campesinos en los años cincuenta fue considerada 
como iniciativa de violencia, porque las acciones de los chulavitas y los pájaros eran legítimas, porque provenía del ejército del bien.

En 1942, Gómez hizo la declaración de su doctrina política en el Senado, de la siguiente manera:

Yo hablo en nombre de los principios de la doctrina católica, que están expresados en las obras filosóficas de Santo Tomás, que dice cómo debe organizarse un Estado (citado por Pérez, 2003).

Con esta confesión de fe, de fe política, Gómez revela el origen de su combate, que no reconoce el Estado como obra de los hombres y que vincula a la Iglesia católica, como portadora de la verdad infalible, al ordenamiento jurídico. Al respecto, la investigadora María del Rosario Vásquez (2007) encuentra que la participación de la Iglesia en las guerras en Colombia, desde el siglo XIX, no fue solamente, como se ha querido hacer ver, cosa de luchas por el poder:

[La historiografía reciente sobre la Iglesia deja] de lado aspectos tan importantes como la historia de las ideas religiosas, la actuación de destacadas personalidades de la jerarquía eclesiástica, el contexto internacional de la historia de la Iglesia colombiana y los matices y diferencias del proceder pastoral de los obispos en tiempos de crisis, de acuerdo con las circunstancias regionales, personales, etc. (pp. 313-314).

Y es claro que el problema no se puede resolver mediante el mismo baremo que se usa para analizar muchos otros acontecimientos históricos. No cabe simplemente acusar a la Iglesia de luchar contra el poder liberal porque había perdido los bienes de manos muertas, lo que le significó un golpe a su patrimonio. Por eso hemos querido referenciar otros motivos, desde el maniqueísmo que trasciende a la Iglesia a través de Pablo de Tarso y de Agustín de Tagaste, y que origina en ella un espíritu apologético, combativo contra lo que consideró el mal.

Antonio Caballero, en su columna de la revista Semana, ha comparado en repetidas ocasiones a Álvaro Uribe con Laureano Gómez para asegurar que Uribe no quiere la paz. Nunca la ha querido y nunca la querrá, como Gómez nunca quiso la paz, porque para este la 
única paz posible era la paz del bien, la paz católica. Todo intento de otra paz no era admisible, porque sería la imposición del mal, del liberalismo masónico, del socialismo ateo que hoy se viste con el apelativo de castrochavismo; un castrochavismo que quiere "entregarle el país a La Far". Caballero recuerda el discurso que se conoce como "El basilisco", de Laureano Gómez, del cual cita una de sus más famosas sentencias:

Y en eso sigue, resucitando con su invento del castrochavismo santista la tesis laureanista del basilisco liberal, que condujo entonces a la Violencia. "Nuestro basilisco -peroraba Laureano- camina con pies de confusión y de ingenuidad, con piernas de atropello y de violencia, con un inmenso estómago oligárquico, con un pecho de ira, con brazos masónicos, y con una pequeña, diminuta cabeza comunista, pero que es la cabeza" (Caballero, 2016).

Del mismo modo, recuerda Caballero que Laureano firmó los acuerdos que dieron vida al Frente Nacional, para después oponerse a ellos (Caballero, 2016b). Se trataba de hacer "invivible la república”. Un acuerdo con el liberalismo solo podía ser una táctica de guerra, no un pacto estratégico respetuoso del oponente político.

\section{El nacionalismo católico de Gómez}

Antes de Gómez Castro, en la década de los veinte, los llamados leopardos desplegaron una actividad belicista, inspirados por el nacionalismo católico y posteriormente por el fascismo. Este grupo tuvo influencia en un personaje que no fue propiamente fascista, Gilberto Alzate Avendaño, y luego en Laureano Gómez (Arias Trujillo, 2007). No obstante, el nacionalismo de Gómez no fue propiamente nazi o fascista, sino católico (Pérez, 2003). En efecto, Hésper Eduardo Pérez demuestra que:

lo que guía a Gómez no es simplemente la reconquista del poder para el Partido Conservador sino sustituir la tradición liberal-individualista del Estado colombiano por la que consideraba nuestra verdadera tradición: la comunidad nacionalista católica (2003, p. 31). 
Esta posición de Gómez la relaciona el autor con la discusión en Francia a principios del siglo xx. Pérez cita a Birnbaum (1991) para describir la tendencia que surge en Europa que se divide en dos alas: la individualista liberal, heredera de la Revolución francesa, y la "comunitaria" que defiende la identidad local frente al universalismo de la Ilustración. Esta última se localiza especialmente en Alemania, que se mantiene comunitaria hasta Weimar, y que intenta imponer una perspectiva liberal. Frente a esta tendencia individualista, se alza Hitler con un comunitarismo que reivindica la identidad alemana y que desemboca en el racismo nazi. En Francia, ante el individualismo liberal universalista de la revolución, se alza un nacionalismo comunitarista y esas dos tendencias se enfrentan a muerte en la guerra de 1870-1871. Pero la rebelión nacionalista que se apropió del modelo comunitarista fue derrotada por el liberalismo. Dice Pérez que la vieja Gemeinschaft (comunidad) fue derrotada por la moderna Gesselschaft (empresa). Pérez agrega que el Partido Conservador de Gómez se aferró a una postura comunitarista, impulsado por la Iglesia intransigente, contra el universalismo individualista liberal.

Cuando Laureano Gómez regresó de Alemania, en 1932, y se ubicó en la oposición del gobierno de Olaya Herrera, venía impregnado de esa perspectiva que se opone al espíritu de la Ilustración:

desde el siglo XVIII, se han empleado en socavar y desacreditar nuestro imperio espiritual, disminuir los grandes valores humanos de nuestra cultura, los descubrimientos, avances y proezas de nuestro genio y las empresas acabadas por la inteligencia y la espada de los hombres de nuestra raza... La historia colombiana, vista a la luz de este criterio, no resulta otra cosa que la crónica de las acometidas insistentes y rabiosas del enemigo externo, adelantadas con la esencia de la patria por los propios hijos de este suelo (citado por Pérez, p. 33).

Para Gómez, el liberalismo que había impuesto Santander desde 1821, cuando empezó su gobierno, se oponía a la tradición española católica, y pretendía imponer las ideas del jacobinismo liberal de la Ilustración, que no desembocarían sino en el socialismo y el comunismo ateos. 
Quieren borrar de la mente popular toda idea divina y reemplazar en el alma de las naciones la doctrina del Calvario por una moral racionalista, colocando, en vez de los resortes de la fe el apetito, y en vez de mostrar en lontananza la existencia de una nueva vida, ponen el acicate del placer y el goce físico (citado por Pérez, 2003, p. 33).

Cabe resaltar la forma que utiliza Gómez para referirse a las ideas a las que se opone, que revelan un espíritu asustado por la avalancha de cambios y de innovaciones que parecen oponerse al espíritu cristiano, y todo lo que pudiera contrariar a este provenía necesariamente del otro espíritu, del mal, es decir, del demonio. De esta forma, se refiere a la Constitución de Cúcuta de 1821 como que en ella "se impuso la perfidia del núcleo santanderista y masónico, que dejaban su camino expedito para ulteriores fines de agitaciones irreligiosas”. Para él, el liberalismo masónico, por ser contrario a la Iglesia, era del mal y, por tanto, terminaría en el comunismo. Sobre esta misma Constitución, dice: "Fue la consagración de la supremacía de las leyes positivistas —cualesquiera leyes sobre las eternas leyes morales-". Para él, la moral eterna es la católica, de modo que cualquier otra moral que pretenda remplazarla es obra del espíritu del mal. La Constitución liberal de Rionegro para Gómez es un "código monstruoso", con el cual los liberales quisieron "mantener su predominio y propagar principios absurdos de filosofía”. Y, en cambio, la Constitución de 1886 fue "la obra cumbre de la inteligencia nacional”, y "la primera síntesis consciente de la personalidad jurídica de Colombia" (las citas son de Pérez, 2003 , p. 34). Conviene resaltar el tono admonitorio y, por supuesto, inquisidor de estas ideas: "perfidia del núcleo santanderista y masónico", “código monstruoso", "principios absurdos”. Gómez quería hacerle la guerra al mal.

El aplauso de Gómez a la Constitución de 1886 hace pensar que fue Miguel Antonio Caro su verdadero antecesor y por eso militó en las filas de su nacionalismo católico, contra la postura "histórica" de los conservadores antioqueños, como Marceliano Vélez y el propio Manuel Antonio Sanclemente, a quien Caro lanzó a la presidencia de la república pensando que la edad y el estado de salud del viejo no le permitirían 
ejercer el mandato y sería Marroquín quien, en efecto, sería el presidente (Morales Benítez, 1998). Ese nacionalismo que protegió la Iglesia, que consideraba que el Estado era obra de Dios y que la nación debía ser salvada del ateísmo liberal, es la bandera que defiende Gómez como única verdad posible, frente al error maligno del liberalismo ilustrado, que era opuesto a Dios y, por consiguiente, debía ser eliminado si se quería salvar la patria. Y por estos principios, su guerra es una guerra santa.

El nacionalismo de Caro y de Gómez tuvo otros nacionalismos oponentes que se sintetizan en la frase de López Pumarejo: "Colombia primero para los colombianos” (López Pumarejo, 1979), que coincide con el nacionalismo de Jorge Eliécer Gaitán, quien le hace una oda a la patria contra todos los imperialismos. Ese nacionalismo liberal es, en todo caso, abierto al mundo y a la modernización. En cambio, el nacionalismo de Caro y de Gómez es chovinista y xenófobo.

Conviene hacer un puente, como lo hace Antonio Caballero, entre Álvaro Uribe y Laureano Gómez, porque los elementos que defendía Caro a finales del siglo xIX y que condujeron a la Constitución de 1886 y a la hegemonía conservadora de más de cuarenta años, que tuvieron que vencer en la guerra a los liberales, derrotados militar y políticamente, y los mismos elementos que defendió Gómez, que desembocaron en el Frente Nacional en pacto con el mortal enemigo y los cuales, finalmente, fueron derrotados por la Constitución de 1991, son los que Uribe pretende revivir en un ataque frontal a esta Constitución, al liberalismo y al Estado social de derecho, al que opone un Estado comunitario, como el que quiso imponer en sus gobiernos. Ese mismo espíritu combativo y apologético de Gómez es hoy el enemigo de la paz, porque esta significa el triunfo del liberalismo y del castrochavismo comunista y, por consiguiente, ateo.

Esta es, pues, también, una guerra santa.

\section{La política del blanqueamiento}

Por último, cabe hacer referencia a un aspecto de la perspectiva de Gómez, que ya se manifestaba en la política conservadora del siglo XIx, en la Constitución de 1886 y en la política de los gobiernos de las primeras tres décadas del siglo xx: la política del blanqueamiento. 
$\mathrm{Al}$ revisarse las diferentes - $\mathrm{y}$ abundantes- constituciones políticas nacionales del siglo XIX, encontramos en estas a indígenas que fueron considerados como nacionales y ciudadanos en condición similar a la de ser "menores de edad", en tanto que los negros solo fueron contemplados como nacionales y, finalmente, como ciudadanos, a partir de la segunda mitad del siglo. La última de estas, que cierra el siglo XIX, recibe el xx y tuvo vigencia durante 105 años, la Constitución de 1886, no expone explícitamente un criterio de exclusión, pero restringe la ciudadanía:

Artículo 15. Son ciudadanos los colombianos varones mayores de veintiún años que ejerzan profesión, arte u oficio, o tengan ocupación lícita u otro medio legítimo y conocido de subsistencia (1886).

En esta definición de ciudadanía se limita a todas las personas que no tengan una profesión liberal, arte u oficio, que no tengan ocupación reconocida, como los indígenas y los afrocolombianos en su gran mayoría. Por supuesto, las mujeres no tienen derecho de elegir ni ser elegidas, como no lo tenían todos los otros menores de edad. En este sentido, esta Constitución establecía un estado para una sola raza, con un solo dios, de un solo sexo y de edad adulta.

Los demás, claro está, estaban excluidos de la vida pública. Y esta era la Constitución perfecta para Laureano, la que él consideraba como salvadora de la patria.

Es preciso recordar que la independencia de Colombia de España no significó de inmediato la liberación de la esclavitud. Solo en 1851, el presidente José Hilario López firmó la ley que entró en vigencia en enero de 1852. López fue opositor de Bolívar, ante quien se levantó en armas, y promovió la Constitución liberal que separó la Iglesia del Estado, puso la educación en manos de este, liberó a los esclavos, declaró la libertad de prensa y federalizó la nación. La abolición de la esclavitud produjo la reacción inmediata de la vertiente conservadora con la rebelión armada dirigida por Julio Arboleda Pombo, conservador nacido en Timbiquí, Cauca, que resultó derrotada por el Gobierno. Arboleda fue un hacendado esclavista, cuya carrera política lo llevó a ser elegido presidente de la Confederación Granadina, fundada por la Constitución liberal. Tras derrotar al presidente de Ecuador en la 
batalla de Tulcán, en su regreso a Bogotá fue asesinado en el mismo lugar en que habían matado al mariscal Sucre.

La reacción esclavista conservadora, sin embargo, no responde a las mismas consideraciones de la Iglesia, que intentaba bautizar a los indios en las selvas, y los jesuitas, por ejemplo, conservaban las reducciones indígenas en los Llanos Orientales. Pero esos indígenas eran considerados por la Iglesia criaturas desvalidas, cuyas culturas rendían culto a ídolos y no eran fáciles de convertir al cristianismo. La Iglesia no quería a los indígenas como esclavos, sino como siervos. Y esta fue la posición de Laureano Gómez.

Vale la pena traer las ideas desesperanzadas de un Laureano Gómez que en 1928, cuando pronuncia su conferencia "Interrogantes sobre el progreso de Colombia" ante el público asistente al Teatro Municipal de Bogotá, se lamenta de las nefastas sombras que significan para el destino del país su conformación biológica.

Para él, el indígena responde a esa raza primitiva que habita, aislada, la selva llena de terror, "entre un cosmos hostil y los seres fantásticos y tenebrosos que son las divinidades de su ruda mitología" (p. 9); que representan "una profunda inercia para la cultura, una letargia invencible. Los hábitos animales dominan al hombre animal” (p. 10). Por su parte, el negro

constituye una tara: en los países de donde él ha desaparecido, como en la Argentina, Chile y Uruguay, se ha podido establecer una organización económica y política con sólidas bases de estabilidad. La culpa del atraso corresponde al pueblo, que frustra una y otra vez los heroicos esfuerzos de nuestras élites (p. 20).

Y, en cuanto se trata del mestizo, este

no constituye un elemento utilizable para la unidad política y económica de América Latina: conserva demasiado los defectos indígenas: es falso, servil, abandonado y repugna todo esfuerzo y trabajo. Sólo en cruces sucesivos de estos mestizos primarios con europeos se manifiesta la fuerza de caracteres adquirida por el blanco (p. 21). 
Esta posición de Laureano coincide con el racismo del nacionalismo europeo conservador, especialmente alemán, con el racismo falangista y con la política elitista de la república conservadora.

La culminación de este capítulo con la referencia al racismo y al blanqueamiento de la política elitista de la perspectiva conservadora, se refiere a la consideración de una naturalización de las capacidades humanas, y aún de sus ideas. Cuando se le adjudica a la raza la posibilidad de progreso se dice que la posición en la sociedad corresponde a natura y que hay unas personas que nacieron para mandar y otras para obedecer, que en la sangre reside la capacidad de un alma sublime o de un cuerpo pecador.

Nuestra raza proviene de la mezcla de españoles, de indios y de negros. Los dos últimos caudales de herencia son estigmas de completa inferioridad. Es en lo que hayamos podido heredar del espíritu español donde debemos buscar las líneas directrices del carácter colombiano contemporáneo (1928, p. 18). 